\begin{tabular}{|c|l|}
\hline Title & Kinetic studies on the CO oxidation on a Rh(111) surface by means of angle resolved thermal desorption \\
\hline Author(s) & Matsushima, Tatsuo; Matsui, Toshiji; Hashimoto, Masanori \\
\hline Citation & $\begin{array}{l}\text { Journal of Chemical Physics, 81(11), 5151-5160 } \\
\text { https://doi.org/10.1063/1.447462 }\end{array}$ \\
\hline Issue Date & 198412-01 \\
\hline Doc URL & http://hdl.handle.net/2115/6054 \\
\hline Rights & Copyright $\odot$ 1984 A merican Institute of Physics \\
\hline Type & article \\
\hline File Information & JCP81-11.pdf \\
\hline
\end{tabular}

Instructions for use 


\title{
Kinetic studies on the CO oxidation on a Rh(111) surface by means of angle-resolved thermal desorption
}

\author{
Tatsuo Matsushima, Toshiji Matsui, and Masanori Hashimoto \\ Research Institute for Catalysis, Hokkaido University, Sapporo 060, Japan
}

(Received 13 January 1984; accepted 2 July 1984)

\begin{abstract}
The kinetics of the reaction of adsorbed $\mathrm{CO}$ with oxygen adatoms was studied in the temperature range of 100-600 K with LEED and angle-resolved thermal desorption. At small oxygen coverages the $\mathrm{CO}_{2}$ formation peaked from 500 to $400 \mathrm{~K}$ with increasing $\mathrm{CO}$ exposure. The activation energy decreased from 45 to $35 \mathrm{kcal} / \mathrm{mol}$. When the oxygen coverage was large, a new $\mathrm{CO}_{2}$ formation peak appeared around $400 \mathrm{~K}$. The activation energy was $30 \mathrm{kcal} / \mathrm{mol}$. LEED observations revealed that the surface was covered by separate domains of $\mathrm{CO}$ and oxygen. The former $\mathrm{CO}_{2}$ is produced outside the domains or on the perimeters, whereas the latter is formed in the oxygen domains. The angular distribution of the desorption of $\mathrm{CO}_{2}$ in the former varied as $\cos ^{4} \theta$, where $\theta$ is the desorption angle. The desorption of $\mathrm{CO}_{2}$ in the latter showed a sharper angular distribution of $\cos ^{15} \theta$.
\end{abstract}

\section{INTRODUCTION}

The energy distribution of desorbing product molecules gives a microscopic insight into the dynamics of surface reactions. The determination of the angular distribution of the desorption flux is the first step in the analysis of the translational energy. ${ }^{1,2}$ From this distribution, it can be examined whether the product is trapped on the surface after the formation. If it is trapped, the molecule would lose kinetic information of the reaction. On the other hand, it would hold information in the energy states, if it desorbs directly from the activated state. In this case the angular distribution at times becomes sharp along the surface normal, i.e., desorbing molecules have an excess translational energy perpendicular to the surface. Recent work by Comsa's grou ${ }^{3-6}$ has shown that a simple one-dimensional model proposed by Willigen ${ }^{1}$ can be used as a prototype to explain the angular and velocity distributions. This model, however, must be modified by considering several factors, i.e., the vibrational modes of activated complexes, ${ }^{7}$ the interaction between gas molecules and surfaces, ${ }^{8,9}$ and the potential energy profiles in the neighborhood of desorption sites. ${ }^{10}$ The potential energy converted into the translational form can be roughly estimated from the angular distribution.,

The $\mathrm{CO}$ oxidation over noble metals is a suitable model for this kind of study, because the product $\mathrm{CO}_{2}$ interacts only weakly with the surfaces. ${ }^{11-15} \mathrm{On} \mathrm{Pt}$, the angular distribution is very sharp along the surface normal, ${ }^{16,17}$ whereas it follows a simple cosine form on Pd. ${ }^{18}$ Time of flight measurements ${ }^{19}$ with a Pt foil at $880 \mathrm{~K}$ revealed that the product $\mathrm{CO}_{2}$ desorbed perpendicular to the surface held an excess translational energy of about $7 \mathrm{kcal} / \mathrm{mol}$. The above results were obtained by molecular beam scattering. This method can be applied only at relatively high temperatures, where the steady product formation is significant. On the other hand, the angle-resolved thermal desorption ${ }^{12,14}$ is useful for a study over a wide coverage range of the reactants and at low temperatures. In a previous paper ${ }^{14}$ we reported the angular distribution of the desorption of $\mathrm{CO}_{2}$ produced on polycrystalline rhodium surfaces. $\mathrm{CO}_{2}$ produced by heating coadsorbed layers of $\mathrm{CO}$ and oxygen showed two peaks, depend- ing on the surface coverages. The desorption of $\mathrm{CO}_{2}$ in the two peaks showed very sharp and different angular distributions. Neither kinetic analysis of the reaction rate, nor precise determination of the angular distribution was given, because these peaks overlapped. In the present paper, we will report a detailed analysis of the kinetic results on a $\mathrm{Rh}(111)$ surface and the angular distribution of $\mathrm{CO}_{2}$ desorption, where the two $\mathrm{CO}_{2}$ peaks can be separately studied. Furthermore, the adsorption structures are analyzed.

\section{EXPERIMENTAL}

The experimental apparatus and procedures were essentially the same as those reported previously. ${ }^{12,14}$ Briefly, the apparatus consisted of a reaction chamber, an analyzer chamber, and a collimator placed between them. These were all separately pumped out. The first had LEED-AES optics, an $\mathrm{Ar}^{+}$gun and a mass spectrometer. The single crystal sample was a disk-shaped slice $(7 \mathrm{~mm}$ diameter $\times 0.5 \mathrm{~mm}$ thickness, purity $99.995 \%$ from Metal Crystal Ltd., UK). Both faces were polished with standard metallographic techniques. The sample was set on a rotatable axis perpendicular to the axis of the collimator.

The sample covered by $\mathrm{O}_{2}$ and/or $\mathrm{CO}$ was resistively heated, while the amount of $\mathrm{O}_{2}, \mathrm{CO}$, or $\mathrm{CO}_{2}$ passing through the collimator was monitored with a mass spectrometer in the analyzer chamber (angle-resolved spectra). Desorption spectra were also recorded in an angle-integrated form with a mass spectrometer in the reaction chamber. The latter was used to analyze general features of the $\mathrm{CO}_{2}$ formation and the kinetics of the reaction. The other was used for the determination of the angular distribution of the $\mathrm{CO}_{2}$ desorption. The signal in the angle-integrated form involves the contribution from the side of the sample $(\sim 12 \%$ of the total area.)

\section{RESULTS}

A general overview of the $\mathrm{CO}_{2}$ formation will be summarized in the first section. The other sections will deal in detail with the kinetics of $\mathrm{CO}_{2}$ formation, angular distribution of the $\mathrm{CO}_{2}$ desorption, and adsorption structure analysis by LEED. 


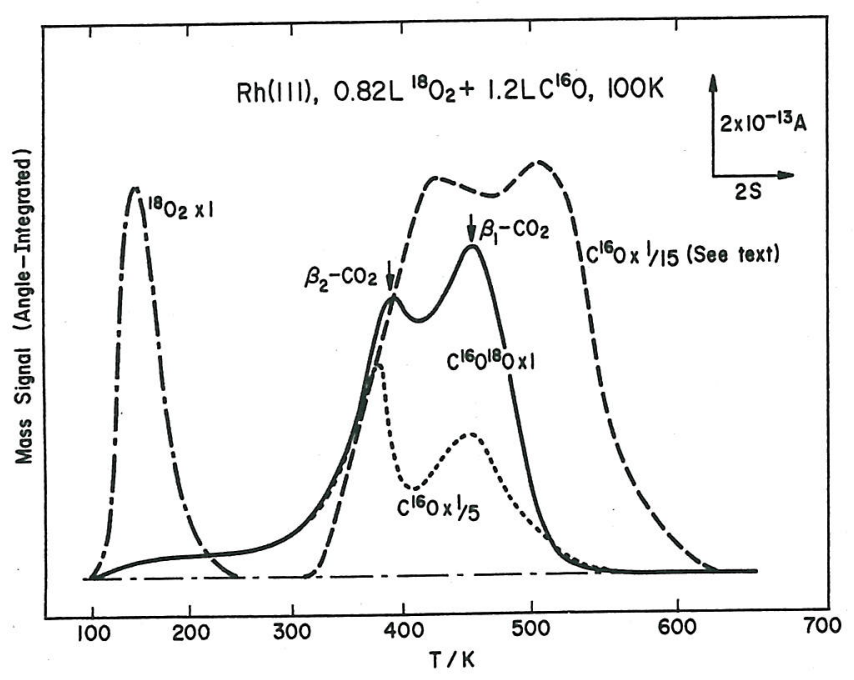

FIG. 1. Typical thermal desorption spectra of ${ }^{18} \mathrm{O}_{2}, \mathrm{C}^{16} \mathrm{O}$, and $\mathrm{C}^{16} \mathrm{O}{ }^{18} \mathrm{O}$ when the surface was exposed to $0.82 \mathrm{~L}^{18} \mathrm{O}_{2}$ and $1.2 \mathrm{~L} \mathrm{C}{ }^{16} \mathrm{O}$ at $100 \mathrm{~K}$. The dashed curve of $\mathrm{CO}$ shows the desorption from a CO-saturated surface without $\mathrm{O}_{2}$ exposure. The heating rate was $33 \mathrm{~K} / \mathrm{s}$.

\section{A. General features}

The general features of $\mathrm{CO}_{2}$ formation on polycrystalline $\mathrm{Rh}$ surfaces ${ }^{14}$ were reproduced on the well-defined (111) surface. The $\mathrm{CO}_{2}$ formation spectra depended strongly on the amount of $\mathrm{CO}$ and $\mathrm{O}_{2}$ exposure, adsorption temperature, and exposure sequence. Typical spectra (in the angle-integrated form) of the desorption of $\mathrm{CO}, \mathrm{O}_{2}$, and $\mathrm{CO}_{2}$ are shown in Fig. 1. The surface was exposed to $0.82 \mathrm{~L}$ (Langmuir) ${ }^{18} \mathrm{O}_{2}$ (the coverage relative to the saturation value determined by TDS was 0.60) at $100 \mathrm{~K}$ and further to $1.2 \mathrm{~L} \mathrm{C}{ }^{16} \mathrm{O}$ (frequently oxygen 16 is simply designated as $\mathrm{O}$ ). It was heated at a constant current up to $1400 \mathrm{~K}$. The temperature increased linearly with a rate of $33 \mathrm{~K} / \mathrm{s}$ below $700 \mathrm{~K}$. The exposure pressure was $2.4 \times 10^{-8}$ Torr for ${ }^{18} \mathrm{O}_{2}$ and $1.0 \times 10^{-8}$ Torr for $\mathrm{CO} . \mathrm{C}^{16} \mathrm{O}{ }^{18} \mathrm{O}$ was produced in the temperature range of $300-500 \mathrm{~K}$. This range is very narrow as compared with that on polycrystalline surfaces. ${ }^{14}$ Neither $\mathrm{C}^{16} \mathrm{O}_{2}$ nor $\mathrm{C}^{18} \mathrm{O}_{2}$ was observed. The usage of ${ }^{18} \mathrm{O}_{2}$ improved the ratio of the signal to the noise of the mass spectrometer highly in the analyzer chamber, because the noise in the $\mathrm{CO}_{2}$ signal was caused by fluctuation of the background level of $\mathrm{C}^{16} \mathrm{O}_{2}$. C ${ }^{16} \mathrm{O}{ }^{18} \mathrm{O}$ peaked around $460 \mathrm{~K}\left(\beta_{1}-\mathrm{CO}_{2}\right)$ and $390 \mathrm{~K}\left(\beta_{2}-\mathrm{CO}_{2}\right)$. The reaction product $\mathrm{C}^{16} \mathrm{O}{ }^{18} \mathrm{O}$ is frequently designated as $\mathrm{CO}_{2}$ in the text. The predominance of $\beta_{1}$ - or $\beta_{2}-\mathrm{CO}_{2}$ depended on $\mathrm{O}_{2}$ and $\mathrm{CO}$ exposure. No $\alpha-\mathrm{CO}_{2}$ formation from the interaction between oxygen admolecules and $\mathrm{CO}^{12}$ was observed. This is probably due to the small amount of molecular oxygen on $\mathrm{Rh}(111) \cdot{ }^{20,21}$ The $\mathrm{O}_{2}$ desorption peaked around 160 $\mathrm{K}$. Another $\mathrm{O}_{2}$ desorption was observed above $800 \mathrm{~K}$ when $\mathrm{CO}$ exposure was small. The former has been assigned to the desorption from adsorbed molecular oxygen. ${ }^{20,21}$ The other is due to the desorption from oxygen adatoms. ${ }^{20-22} \mathrm{CO}$ showed two desorption peaks around 380 and $450 \mathrm{~K}$. The former appeared only when $\mathrm{O}_{2}$ and $\mathrm{CO}$ exposure was large. The latter was attenuated rapidly with increasing exposure of oxygen. By way of comparison, a spectrum of $\mathrm{CO}$ which was desorbed from $\mathrm{CO}$ saturated surface without oxygen

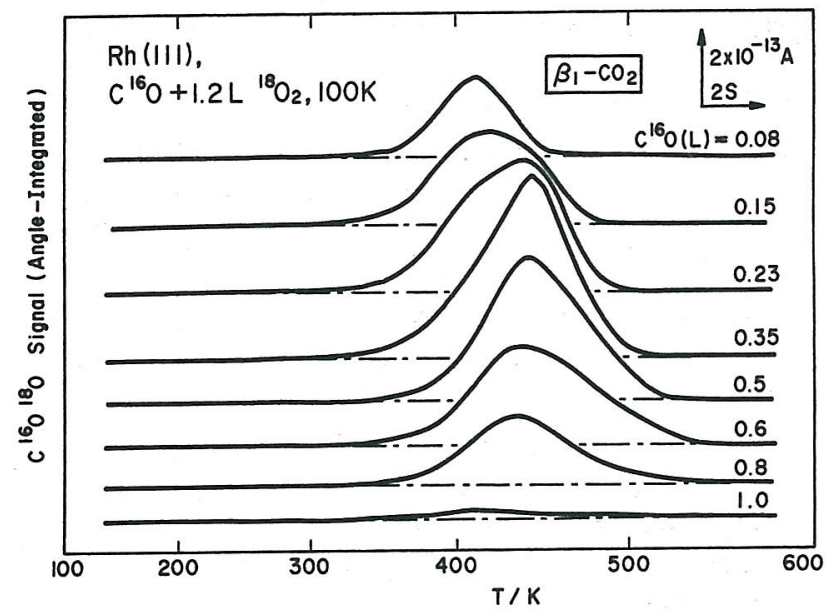

FIG. 2. Variation of $\mathrm{CO}_{2}$ spectra with various $\mathrm{CO}$ preexposures. The surface was first exposed to $\mathrm{CO}$ and then to $1.2 \mathrm{C}^{18} \mathrm{O}_{2}$ at $100 \mathrm{~K}$. The heating rate was $20 \mathrm{~K} / \mathrm{s}$.

exposure $(2.4 \mathrm{~L} \mathrm{CO}$ at $100 \mathrm{~K})$ is shown in the figure. It should be noticed that the pumping rate for $\mathrm{CO}_{2}$ in the reaction chamber was about twenty times as large as that of $\mathrm{CO}$.

When $\mathrm{CO}$ was first dosed, the $\mathrm{CO}_{2}$ spectrum showed a simple behavior. Typical results are summarized in Fig. 2. The amount of $\mathrm{CO}_{2}$ produced increased first with $\mathrm{CO}$ exposure and showed its maximum around $0.35 \mathrm{~L} \mathrm{CO}$. After this point, it decreased and disappeared above $1.0 \mathrm{~L}$. In this case

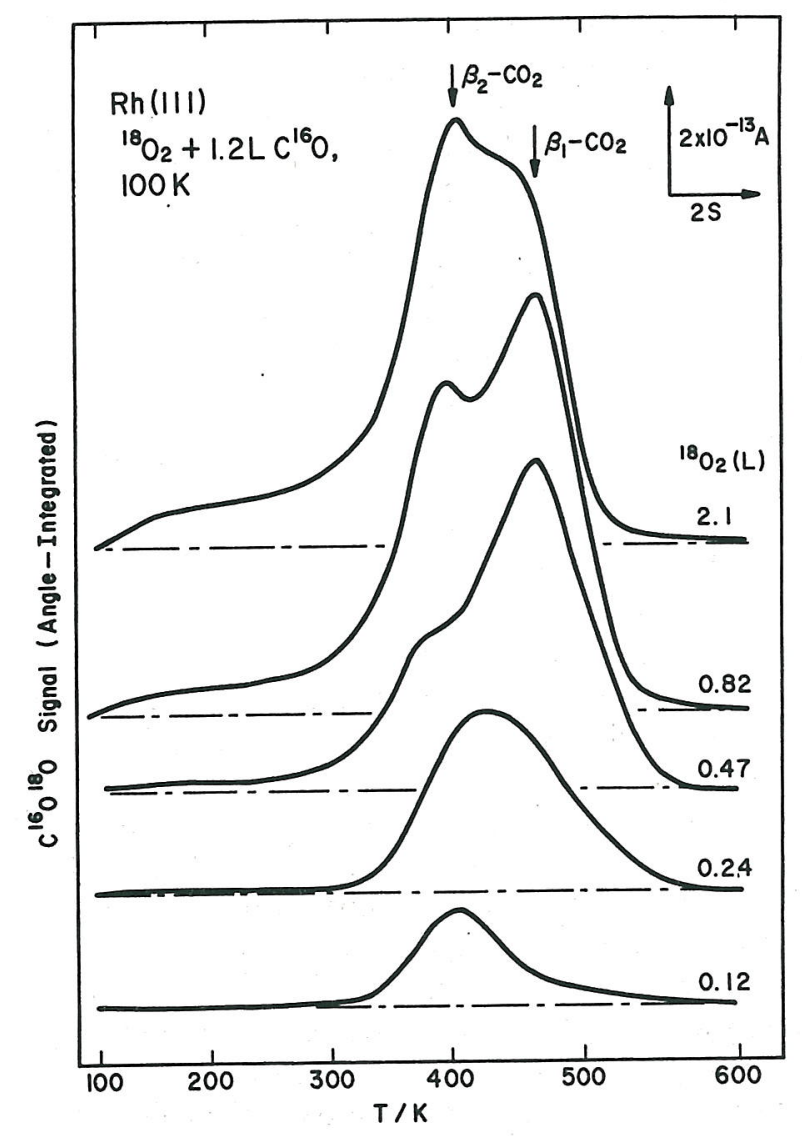

FIG. 3. $\mathrm{CO}_{2}$ formation spectra with various amounts of ${ }^{18} \mathrm{O}_{2}$ exposures followed by $1.2 \mathrm{~L}$ exposure of $\mathrm{C}^{16} \mathrm{O}$ at $100 \mathrm{~K}$. The heating rate was $35 \mathrm{~K} / \mathrm{s}$. 


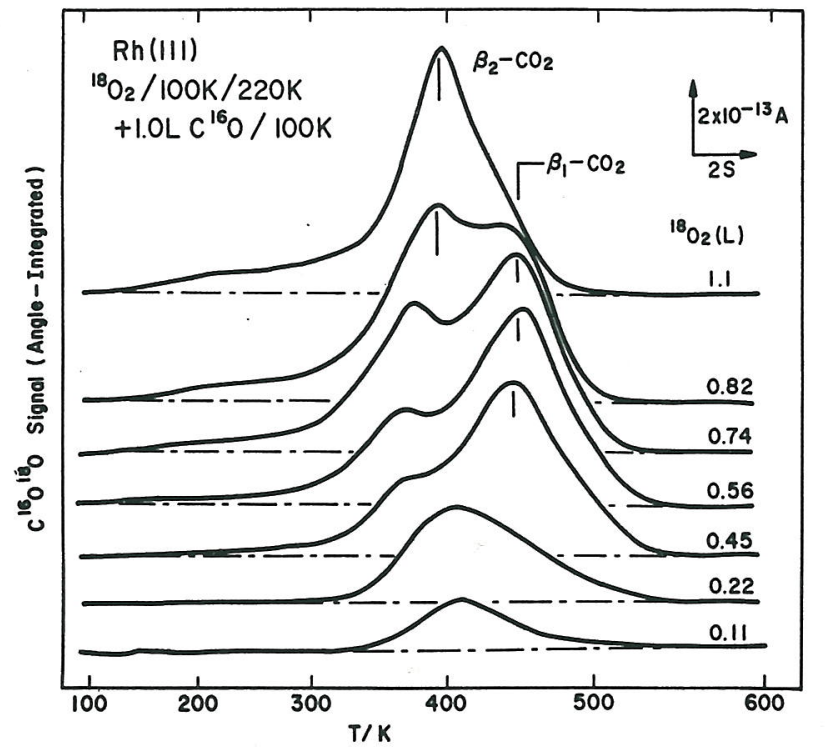

FIG. 4. $\mathrm{CO}_{2}$ formation spectra with various amounts of ${ }^{18} \mathrm{O}_{2}$ exposure at $100 \mathrm{~K}$ followed by heating up to $220 \mathrm{~K}$, and $1.0 \mathrm{~L}$ exposure of $\mathrm{C}^{16} \mathrm{O}$ at 100 $\mathrm{K}$. There is an improved separation of $\beta_{1}-\mathrm{CO}_{2}$ from $\beta_{2}-\mathrm{CO}_{2}$. The heating rate was $28 \mathrm{~K} / \mathrm{s}$.

only $\beta_{1}-\mathrm{CO}_{2}$ was produced. The separation of $\beta_{2}-\mathrm{CO}_{2}$ from $\beta_{1}-\mathrm{CO}_{2}$ became clearer when the surface temperature was raised once up to $220 \mathrm{~K}$ after $\mathrm{O}_{2}$ exposure at $100 \mathrm{~K}$. $\mathrm{CO}_{2}$ spectra with various $\mathrm{O}_{2}$ exposures without such preheating are summarized in Fig. 3. The surface was exposed to various amounts of oxygen and $1.2 \mathrm{~L} \mathrm{CO}$ at $100 \mathrm{~K}$. A single peak $\left(\beta_{1}\right)$ was observed around $400 \mathrm{~K}$ at small $\mathrm{O}_{2}$ exposures. Above $0.47 \mathrm{~L} \mathrm{O}_{2}$ the spectrum became broad with an increase in $\mathrm{O}_{2}$ exposure and showed a shoulder of $\beta_{2}-\mathrm{CO}_{2}$ around $400 \mathrm{~K}$. The peak temperature of $\beta_{1}-\mathrm{CO}_{2}$ shifted from 400 to $470 \mathrm{~K}$. When the surface exposed to $\mathrm{O}_{2}$ in large amounts $\left(>2.0 \mathrm{~L} \mathrm{O}_{2}\right), \beta_{2}-\mathrm{CO}_{2}$ became predominant, but $\beta_{1^{-}}$ $\mathrm{CO}_{2}$ was still significant. On the other hand, $\beta_{1}-\mathrm{CO}_{2}$ mostly disappeared when the surface was heated once to $220 \mathrm{~K}$ after large $\mathrm{O}_{2}$ exposure. Typical $\mathrm{CO}_{2}$ spectra are shown in Fig. 4 . In this case the surface was exposed to various amounts of

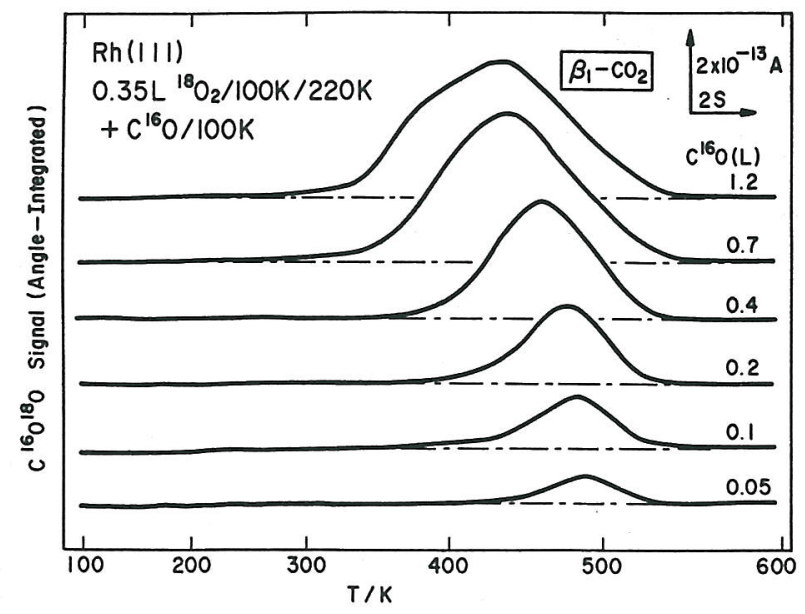

FIG. 5. $\beta_{1}-\mathrm{CO}_{2}$ formation spectra at small $\mathrm{O}_{2}$ exposures. The surface was exposed to $0.35 \mathrm{~L}^{18} \mathrm{O}_{2}$ at $100 \mathrm{~K}$ and heated to $220 \mathrm{~K}$. It was further exposed to various amounts of $\mathrm{CO}$ at $100 \mathrm{~K}$. The heating rate was $22 \mathrm{~K} / \mathrm{s}$.

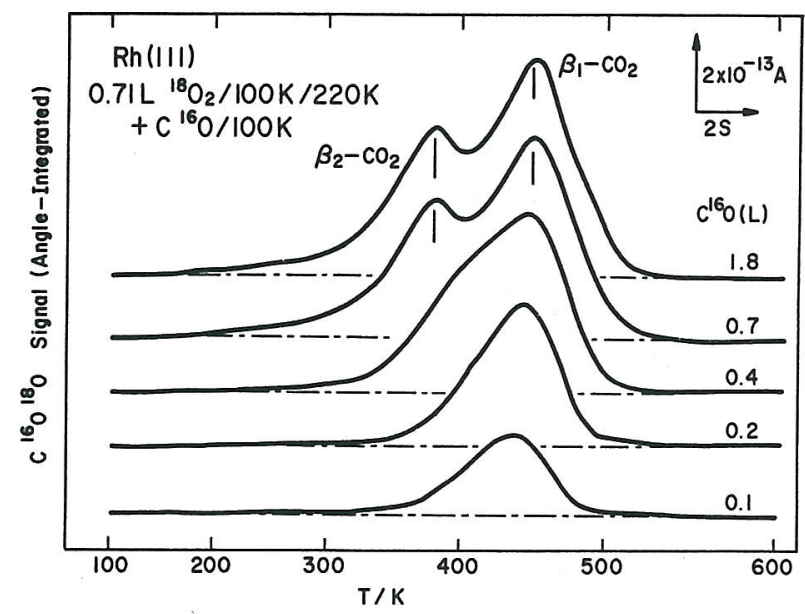

FIG. 6. $\beta_{1}-\mathrm{CO}_{2}$ and $\beta_{2}-\mathrm{CO}_{2}$ formation spectra at moderate $\mathrm{O}_{2}$ exposures. The heating rate was $23 \mathrm{~K} / \mathrm{s}$.

oxygen at $100 \mathrm{~K}$ and heated up to $220 \mathrm{~K}$. $1.0 \mathrm{~L}$ CO was introduced after cooling down to $100 \mathrm{~K}$. No changes in general features were observed. The $\beta_{1}-\mathrm{CO}_{2}$ peak shifted from 400 to $450 \mathrm{~K}$ with increasing $\mathrm{CO}$ exposure. Only $\beta_{2}-\mathrm{CO}_{2}$ was observed above $1.1 \mathrm{~L}$ preexposure of oxygen, where the surface was saturated with oxygen. The better $\beta_{1}-\beta_{2}$ separation was quite reproducible. From now on, the surface was heated up to $220 \mathrm{~K}$ after $\mathrm{O}_{2}$ exposure except for experiments of LEED. $\beta-\mathrm{CO}_{2}$ is formed through the interaction between adsorbed $\mathrm{CO}$ and oxygen adatoms, since oxygen is dissociatively adsorbed above $200 \mathrm{~K}^{20-22}$

Kinetic analysis was carried out in following three regions: (i) Small $\mathrm{O}_{2}$ exposures. The spectra below $0.35 \mathrm{~L}$ preexposure of oxygen showed a single $\beta_{1}-\mathrm{CO}_{2}$ peak, as shown in Fig. 5. The peak temperature shifted from 480 to $430 \mathrm{~K}$ with increasing $\mathrm{CO}$ exposure.

(ii) Moderate $\mathrm{O}_{2}$ exposures. $\mathrm{CO}_{2}$ spectra observed at 0.7 $\mathrm{L}$ preexposure of oxygen and various $\mathrm{CO}$ exposures are shown in Fig. 6 . When CO exposure was small, only the $\beta_{1}$ -

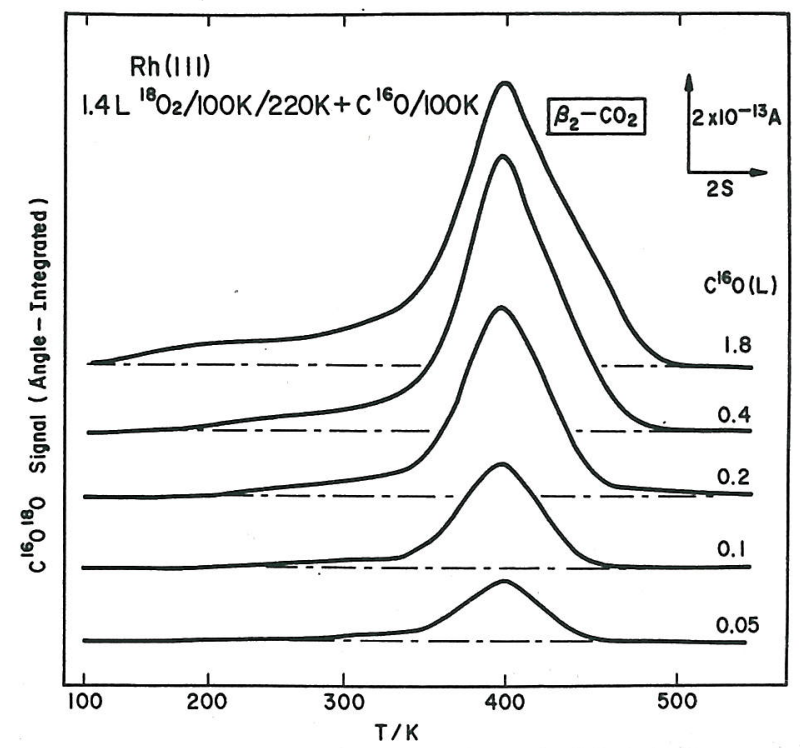

FIG. 7. $\beta_{2}-\mathrm{CO}_{2}$ formation spectra on oxygen-saturated surfaces. The heating rate was $24 \mathrm{~K} / \mathrm{s}$. 
$\mathrm{CO}_{2}$ peak appeared. A shoulder of $\beta_{2}-\mathrm{CO}_{2}$ grew with $\mathrm{CO}$ exposure. $\beta_{1}-\mathrm{CO}_{2}$ remained predominant at large $\mathrm{CO}$ exposures.

(iii) Large $\mathrm{O}_{2}$ exposures. $\mathrm{CO}_{2}$ formation spectra on oxygen-saturated surfaces are shown in Fig. 7. Only $\beta_{2}-\mathrm{CO}_{2}$ was produced irrespective of $\mathrm{CO}$ exposures. No shift of the peak temperature was observed.

\section{B. The activation energy}

The activation energy of $\mathrm{CO}_{2}$ formation was estimated by using an isostere method. ${ }^{23}$ Analysis by means of Redhead's equations ${ }^{24}$ was not performed because the reaction orders with respect to $\mathrm{CO}$ and oxygen were not considered to be constant over a wide range of coverages. In the isostere method, the activation energy is determined from the slope of the logarithm of the desorption rate (reaction rate) measured in a large pumping system against the reciprocal of the temperature at fixed coverages. In the present analysis the logarithm of the peak maximum (the maximum $\mathrm{CO}_{2}$ formation rate) was plotted against the reciprocal of the peak temperature because the amount of $\mathrm{CO}_{2}$ produced was independent of the heating rate and the $\mathrm{CO}_{2}$ peak was fairly symmetrical. The activation energy was determined at three different oxygen exposures. The heating rate ranged from 4 to $150 \mathrm{~K} / \mathrm{s}$. Representative sets of reaction isosteres for the $\mathrm{CO}_{2}$ formation rate are shown in Figs. 8-10. When the oxygen exposure was small, the activation energy for $\beta_{1}-\mathrm{CO}_{2}$ formation ranged from 45 to $35 \mathrm{kcal} / \mathrm{mol}$ with increasing

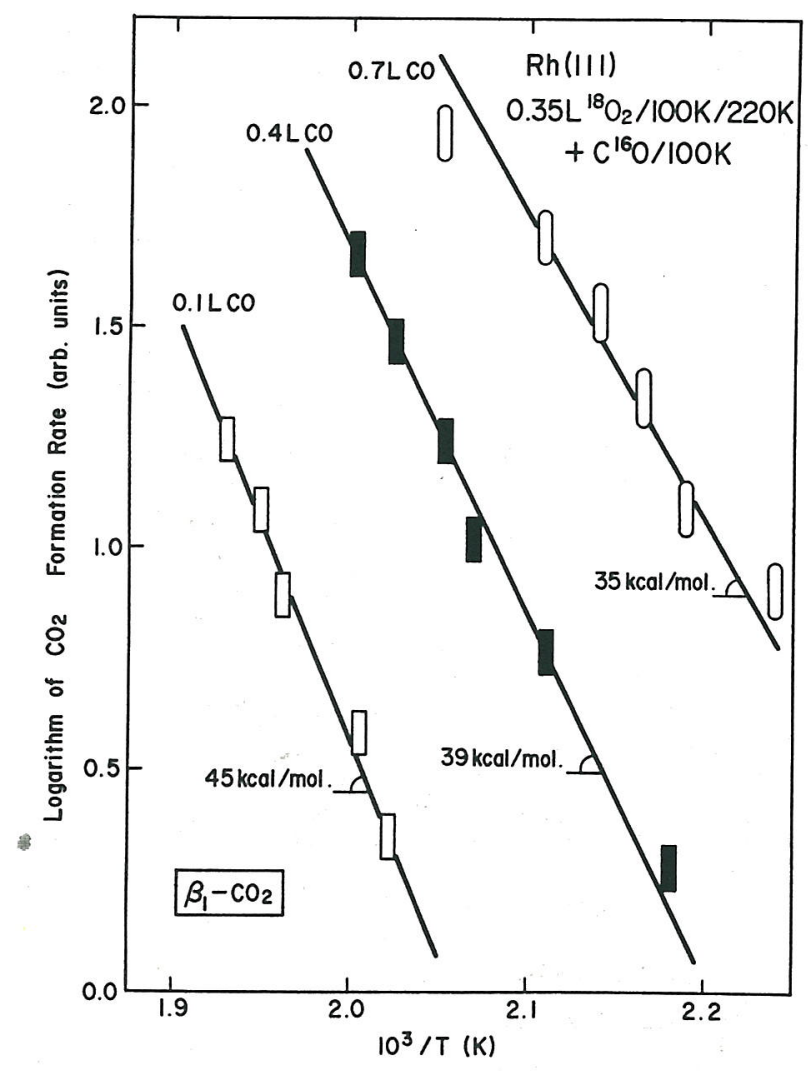

FIG. 8. $\mathrm{CO}_{2}$ reaction isosteres at small $\mathrm{O}_{2}$ exposures. The slope of the linear isostere indicates the activation energies ranging from $35 \mathrm{kcal} / \mathrm{mol}$ for $0.7 \mathrm{~L}$ $\mathrm{CO}$ to $45 \mathrm{kcal} / \mathrm{mol}$ for $0.1 \mathrm{~L} \mathrm{CO}$.

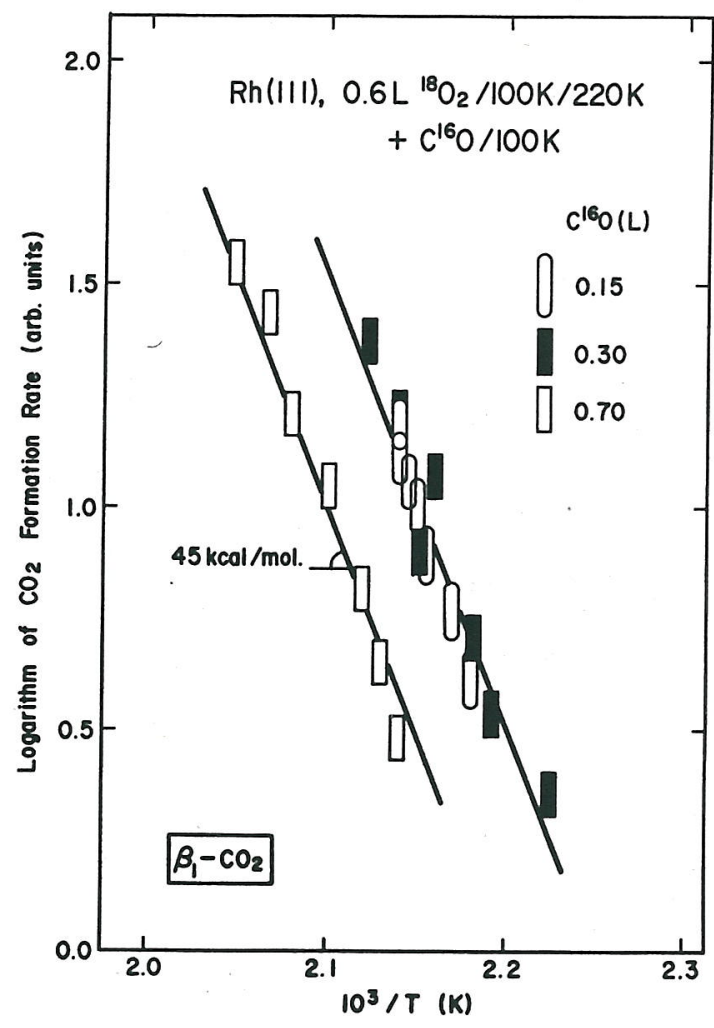

FIG. 9. $\beta_{1}-\mathrm{CO}_{2}$ reaction isosteres at moderate $\mathrm{O}_{2}$ exposures.

$\mathrm{CO}$ exposure, as shown in Fig. 8. At moderate $\mathrm{O}_{2}$ exposures, the activation energy of $\beta_{1}-\mathrm{CO}_{2}$ remained almost constant around $45 \mathrm{kcal} / \mathrm{mol}$ independent of $\mathrm{CO}$ exposure (Fig. 9). Figure 10 shows that the activation energy of $\beta_{2}-\mathrm{CO}_{2}$ forma-

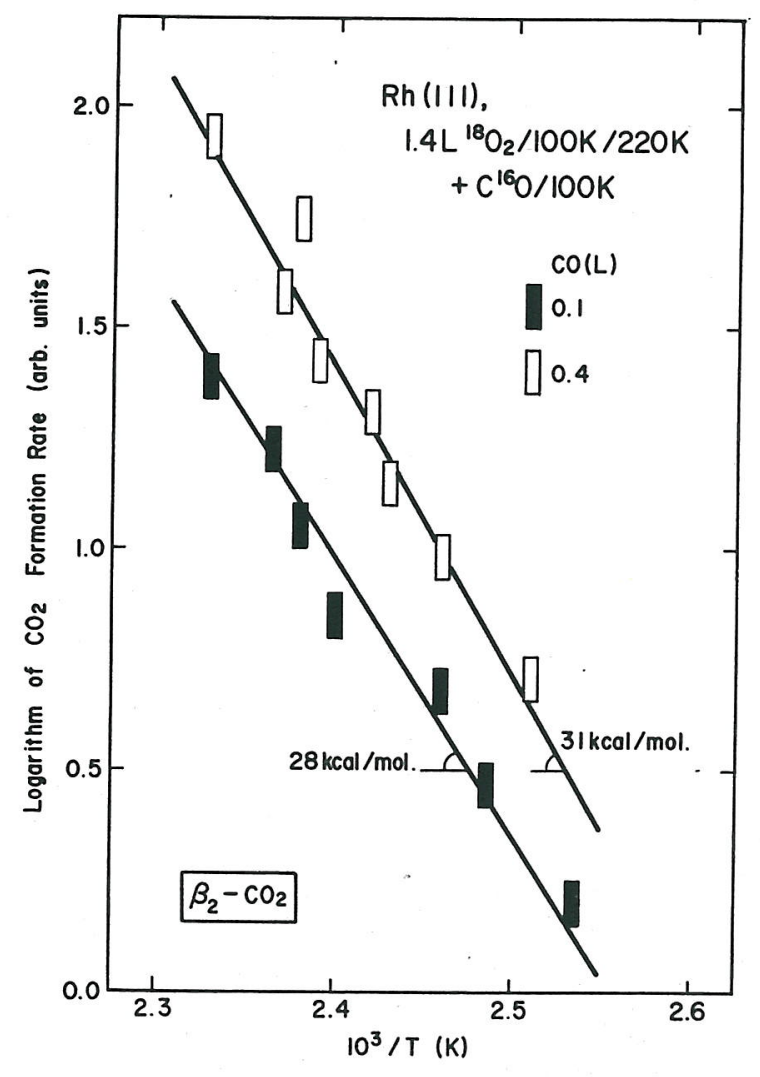

FIG. 10. $\beta_{2}-\mathrm{CO}_{2}$ reaction isosteres on oxygen-saturated surfaces. 
tion on oxygen-saturated surfaces was about $30 \mathrm{kcal} / \mathrm{mol}$, independent of $\mathrm{CO}$ exposure.

\section{Angular distribution of $\mathrm{CO}_{2}$ desorption}

Figure 11 shows $\mathrm{CO}_{2}$ spectra observed at various desorption angles at moderate oxygen exposures. The upper panel shows the angle-resolved spectra and the bottom shows the angle-integrated form. The surface was exposed to $0.6 \mathrm{~L}^{18} \mathrm{O}_{2}$ at $100 \mathrm{~K}$ and heated up to $220 \mathrm{~K}$. C ${ }^{16} \mathrm{O}$ of $1.2 \mathrm{~L}$ was introduced at $100 \mathrm{~K}$ and heated with a rate of $56 \mathrm{~K} / \mathrm{s}$. The $\mathrm{CO}_{2}$ spectrum in the angle-integrated form shows predominantly $\beta_{1}-\mathrm{CO}_{2}$ and a small contribution from $\beta_{2}-\mathrm{CO}_{2}$. It shows the total amounts of $\beta_{1}$ - and $\beta_{2}-\mathrm{CO}_{2}$ formation. On the other hand the $\mathrm{CO}_{2}$ spectrum in the angle-resolved form at $\theta=0(\theta$ is the desorption angle between the surface normal and the collimator axis) consisted of almost equal intensity of $\beta_{1}-\mathrm{CO}_{2}$ and $\beta_{2}-\mathrm{CO}_{2}$. This means that the desorption of $\beta_{2}-\mathrm{CO}_{2}$ is distributed along the surface normal more sharply than $\beta_{1}-\mathrm{CO}_{2}$. The peak height of $\beta_{2}-\mathrm{CO}_{2}$ decreased with increasing $\theta$ more rapidly than that of $\beta_{1}-\mathrm{CO}_{2}$. The angular distribution of $\beta_{1}-\mathrm{CO}_{2}$ showed $\cos ^{4} \theta$ dependence. The distribution from the other was sharper than $\cos ^{8} \theta$. The determination was not reliable in this region, since the $\beta_{2}-\mathrm{CO}_{2}$ peak was obscured by the large $\beta_{1}-\mathrm{CO}_{2}$ peak at large desorption angles. The angular distribution of $\beta_{1}-\mathrm{CO}_{2}$ was studied below $0.6 \mathrm{~L} \mathrm{O}_{2}$, since in this region the $\beta_{1}-\mathrm{CO}_{2}$ formation

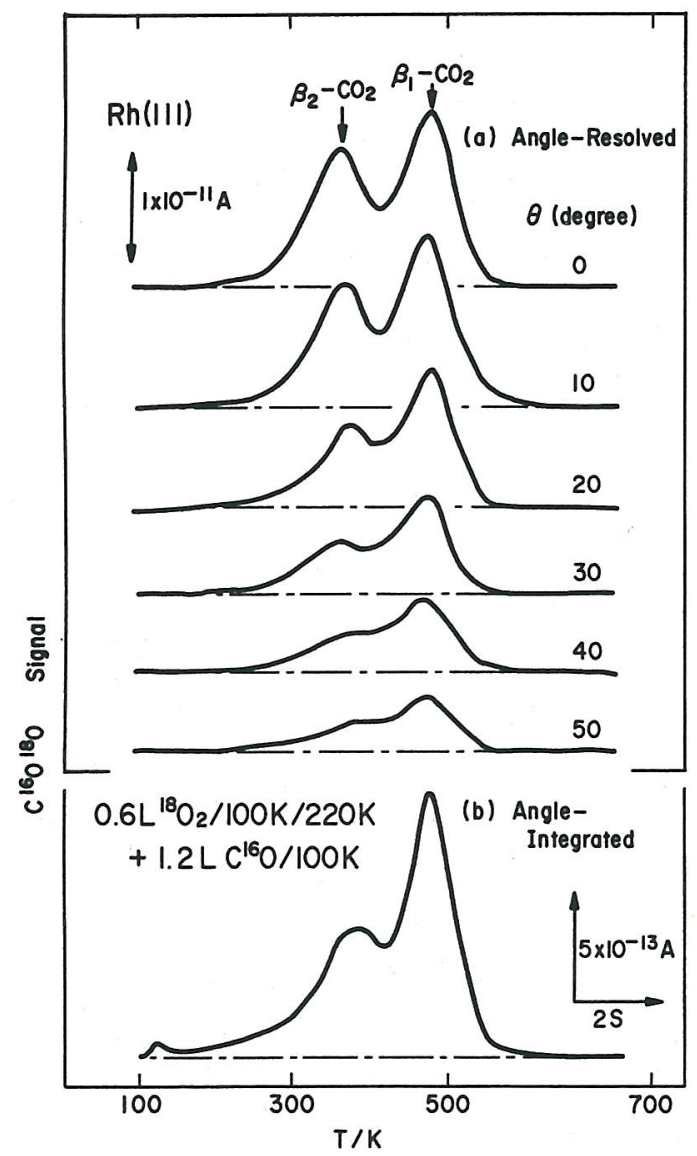

FIG. 11. (a) Angle-resolved $\mathrm{CO}_{2}$ formation spectra observed at various desorption angles. (b) $\mathrm{A} \mathrm{CO}_{2}$ formation spectrum in the angle-integrated form observed simultaneously. The heating rate was $57 \mathrm{~K} / \mathrm{s}$.

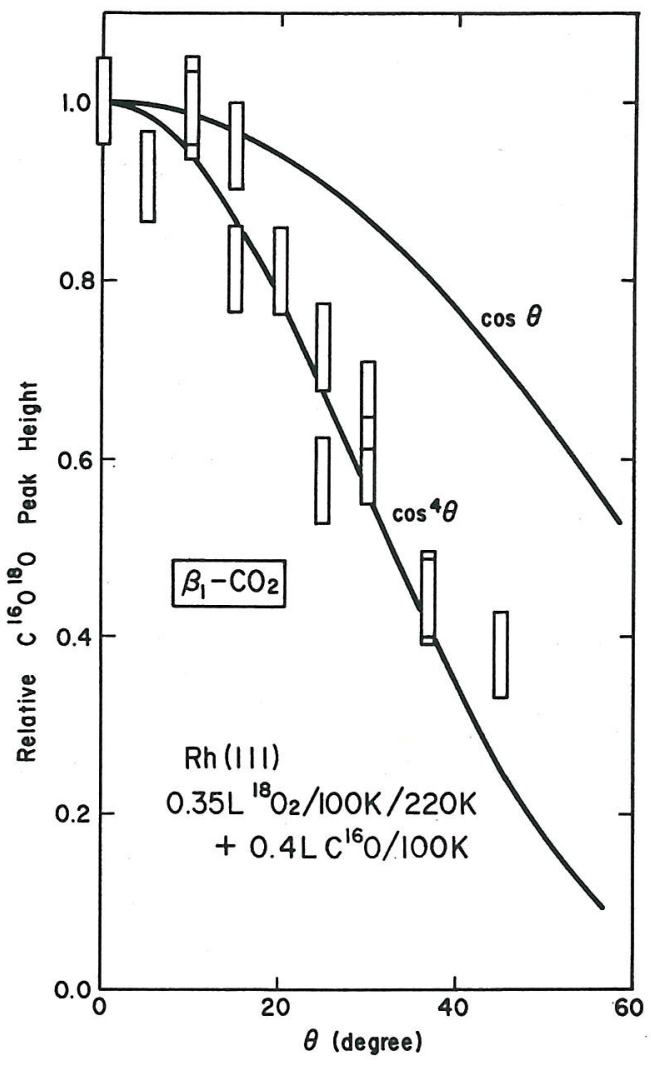

FIG. 12. Angular distribution of the $\beta_{1}-\mathrm{CO}_{2}$ formation.

was predominant. The results obtained at $0.35 \mathrm{~L} \mathrm{O}_{2}$ are summarized in Fig 12, where the relative $\mathrm{CO}_{2}$ peak height is plotted against the desorption angle. The angular distribution varied as $(\cos \theta)^{4 \pm 1}$. The distribution did not vary within the range of $0.2-0.6 \mathrm{~L}$ preexposure of ${ }^{18} \mathrm{O}_{2}$ and $0.1-1.2 \mathrm{~L}$ postexposure of $\mathrm{CO}$. This angular distribution agreed well with previous results on polycrystalline surfaces. ${ }^{14}$ The angular distribution of $\beta_{2}-\mathrm{CO}_{2}$ desorption was determined at $1.4 \mathrm{~L}$ preexposure of $\mathrm{O}_{2}$. Typical $\mathrm{CO}_{2}$ spectra are shown in Fig. 13. The surface was heated up to $220 \mathrm{~K}$ after $1.4 \mathrm{~L}$ preexposure of ${ }^{18} \mathrm{O}_{2}$ and exposed to $0.4 \mathrm{~L} \mathrm{C}{ }^{16} \mathrm{O}$ at $100 \mathrm{~K}$. The heating rate was $90 \mathrm{~K} / \mathrm{s}$. The upper panel shows the

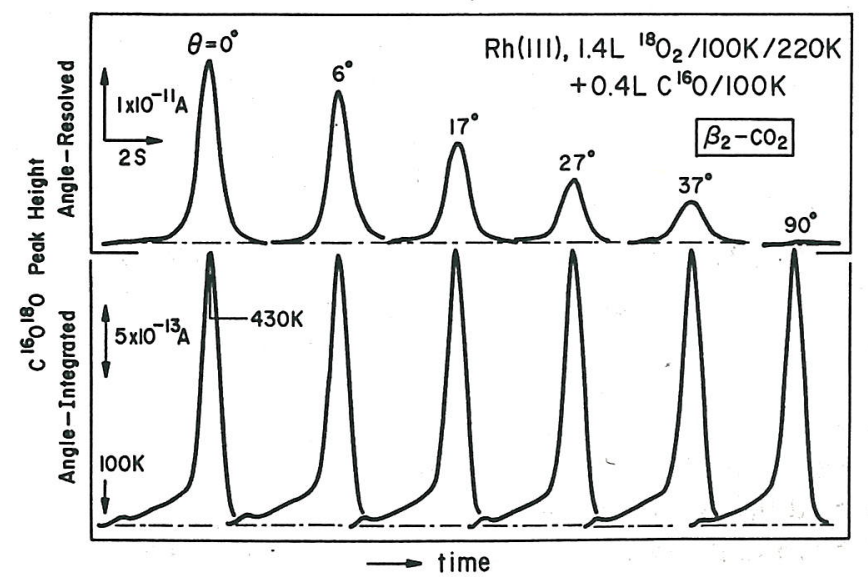

FIG. 13. Typical $\beta_{2}-\mathrm{CO}_{2}$ formation spectra in the angle-resolved form (upper) and also in the angle-integrated form (lower) at various desorption angles. The heating rate was $90 \mathrm{~K} / \mathrm{s}$. 


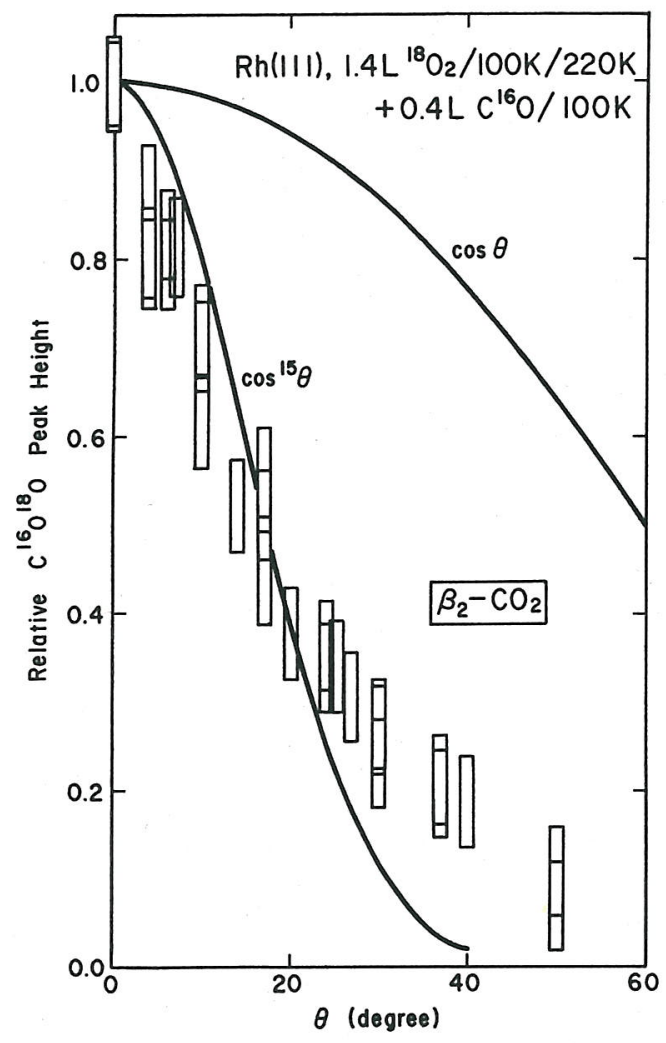

FIG. 14. Angular distribution of the $\beta_{2}-\mathrm{CO}_{2}$ formation. The heating rate was $90 \mathrm{~K} / \mathrm{s}$.

angle-resolved $\mathrm{CO}_{2}$ spectra recorded in the analyzer chamber. The peak height decreased very rapidly with an increase in the desorption angle. The lower panel summarizes the angle-integrated $\mathrm{CO}_{2}$ spectra simultaneously recorded in the reaction chamber. These spectra remained invariant. The signal intensity can not be directly compared with that in the analyzer chamber, because the amplifier system of the two mass spectrometers were different. The relative value of the signal in the angle-resolved spectra is plotted against the desorption angle in Fig. 14. The vertical rectangles indicate the limit of experimental errors. The angular distribution was extremely sharp and varied as $(\cos \theta)^{15 \pm 3}$. This is much sharper than on polycrystalline surfaces. ${ }^{14}$ Such sharper distributions on single crystal surfaces were observed on $\mathrm{Pt}^{12}$ This distribution did not depend on the heating rate in the range of $10-140 \mathrm{~K} / \mathrm{s}$. No coverage dependence was observed in the range of $0.1-1.2 \mathrm{~L} \mathrm{CO}$ exposure.

\section{LEED data}

LEED patterns were always observed at $100 \mathrm{~K}$. A faint $(2 \times 2)$ structure appeared after $\mathrm{O}_{2}$ exposure at $100 \mathrm{~K}$. The spot intensity increased remarkably after heating up to 220 $\mathrm{K}$. This heating removed molecular oxygen ${ }^{20,21}$ and led to a well-ordered $(2 \times 2)$-O structure. ${ }^{22}$ When a clean surface was exposed to $\mathrm{CO}$ at room temperature, $\mathrm{a}(\sqrt{3} \times \sqrt{3}) \mathrm{R} 30^{\circ}$ [abbreviated below to $(\sqrt{3}) \mathrm{R} 30$ ] structure first appeared ${ }^{25}$ around $0.5 \mathrm{~L}$ and the intensity reached its maximum around $1.0 \mathrm{~L}$. On the other hand, a $(2 \times 2)$ structure was observed at $0.2 \mathrm{~L}$ $\mathrm{CO}$ at $100 \mathrm{~K} .{ }^{26}$ This structure coexisted with the $(\sqrt{3}) \mathrm{R} 30$ around $0.45 \mathrm{~L}$. Above this exposure the $(\sqrt{3}) \mathrm{R} 30$ spot was

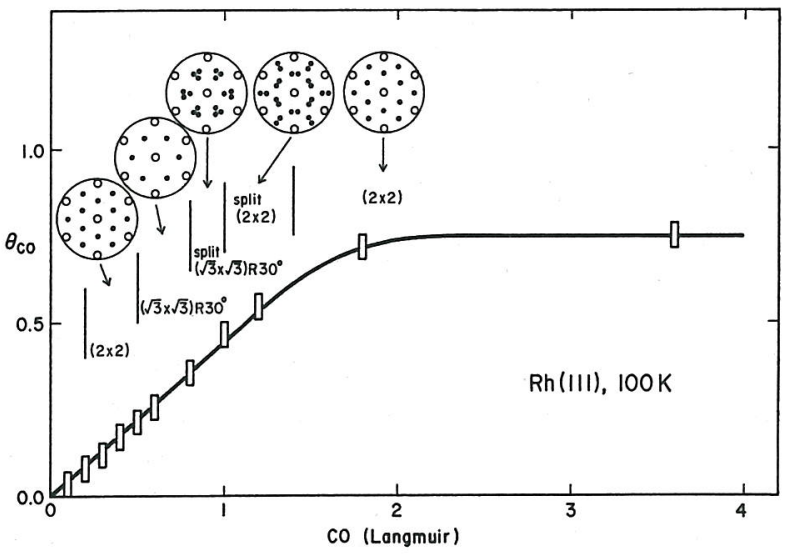

FIG. 15. CO coverage and LEED pattern vs exposure. Open and closed circles indicate diffraction spots due to the base metal and adsorbates, respectively.

very sharp. Above $0.8 \mathrm{~L} \mathrm{CO}$, the spot became broad and split. Finally another $(2 \times 2)$ structure appeared above $1.4 \mathrm{~L}$ $\mathrm{CO}$ after split $(2 \times 2)$. The $(2 \times 2)$ structure appearing at $0.2 \mathrm{~L}$ $\mathrm{CO}$ has a one-fourth monolayer of $\mathrm{CO}$ (the $\mathrm{CO}$ coverage $\left.\theta_{c o}=1 / 4\right)$ and the final $(2 \times 2)$ a three-fourth monolayer $\left(\theta_{\text {co }}=3 / 4\right) \cdot{ }^{26}$ Figure 15 summarizes these results. Vertical bars indicate transition regions around which neighboring patterns were observed simultaneously. The transition from split $(\sqrt{3})$ R30 to split $(2 \times 2)$ was associated with other complex patterns. The amount of $\mathrm{CO}(a)$ was determined by thermal desorption. The maximum amount was adjusted to the coverage $=3 / 4 .^{26}$ The reverse sequence of the LEED patterns was well reproduced when the surface saturated with $\mathrm{CO}$ was heated sequentially to reduce the amount of $\operatorname{CO}(a)$.

LEED patterns showed a complicated behavior when the surface was exposed to both reactants. The superposition of the $(2 \times 2)-O$ and $(\sqrt{3})$ R30-CO was observable when the surface coverages were suitably controlled. The results are listed in Tables I and II. In the former series of experiments the surface was first exposed to $\mathrm{CO}$ and further to $1.4 \mathrm{~L} \mathrm{O}_{2}$ at $100 \mathrm{~K}$. It was heated to desired temperatures and again cooled down to observe LEED patterns. The temperature was raised to the region in which $\mathrm{CO}_{2}$ was formed. In general, $\mathrm{CO}$ adsorption structures were converted to those at higher $\mathrm{CO}$ coverages by $\mathrm{O}_{2}$ adsorption. At $0.4 \mathrm{~L} \mathrm{CO},(2 \times 2)$ CO was converted to the superposition with $(\sqrt{3}) \mathrm{R} 30-\mathrm{CO}$ after $\mathrm{O}_{2}$ adsorption. At $0.5 \mathrm{~L}$ the sharp $(2 \times 2)$-CO disappeared. At $0.6-0.7 \mathrm{~L} \mathrm{CO}$, the sharp $(\sqrt{3}) \mathrm{R} 30-\mathrm{CO}$ was split. These results suggest that $\mathrm{CO}$ domains are compressed by $\mathrm{O}_{2}$ adsorption. After annealing to $390 \mathrm{~K}$, sharp $(2 \times 2)-\mathrm{O}$ appeared when adsorbed oxygen was significant. For example at $0.6 \mathrm{~L} \mathrm{CO}$, split $(\sqrt{3}) \mathrm{R} 30-\mathrm{CO}$ was replaced by the superposition of sharp $(2 \times 2)$ and $(\sqrt{3}) \mathrm{R} 30-\mathrm{CO}$. After heating to $440 \mathrm{~K}$, the $(2 \times 2)$ and $(\sqrt{3})$ R30-CO were observed at almost the same intensity. Further heating lowered the intensity of $(2 \times 2)$ below that of $(\sqrt{3})$ R $30-C O$ and then $(2 \times 2)>(\sqrt{3})$ R $30-C O$. The former $(2 \times 2)$ below $440 \mathrm{~K}$ can be assigned to $(2 \times 2)-\mathrm{O}$ and the latter $(2 \times 2)$ (above $486 \mathrm{~K}$ ) to $(2 \times 2)-\mathrm{CO}$ at $\theta_{\mathrm{co}}=1 / 4$, because $(\sqrt{3}) \mathrm{R} 30-\mathrm{CO}$ never coexists with $(2 \times 2)-\mathrm{CO}$ at $\theta_{\text {co }}=3 / 4$, and further $(2 \times 2)-\mathrm{CO}$ at $\theta_{\text {co }}=1 / 4$ follows $(\sqrt{3}) \mathrm{R} 30-\mathrm{CO}$ when CO coverage decreases. The LEED pat- 
TABLE I. LEED patterns when the surface was exposed to various amounts of $\mathrm{CO}$ and then to $1.4 \mathrm{~L} \mathrm{O}_{2}$ at 100 $\mathrm{K}$. The surface was sequentially heated to $500 \mathrm{~K}$. LEED patterns were observed at $100 \mathrm{~K}$. The maximum intensity of the spots was compared in the range of $20-60 \mathrm{eV}$ of the beam energy. ${ }^{\mathrm{a}}$

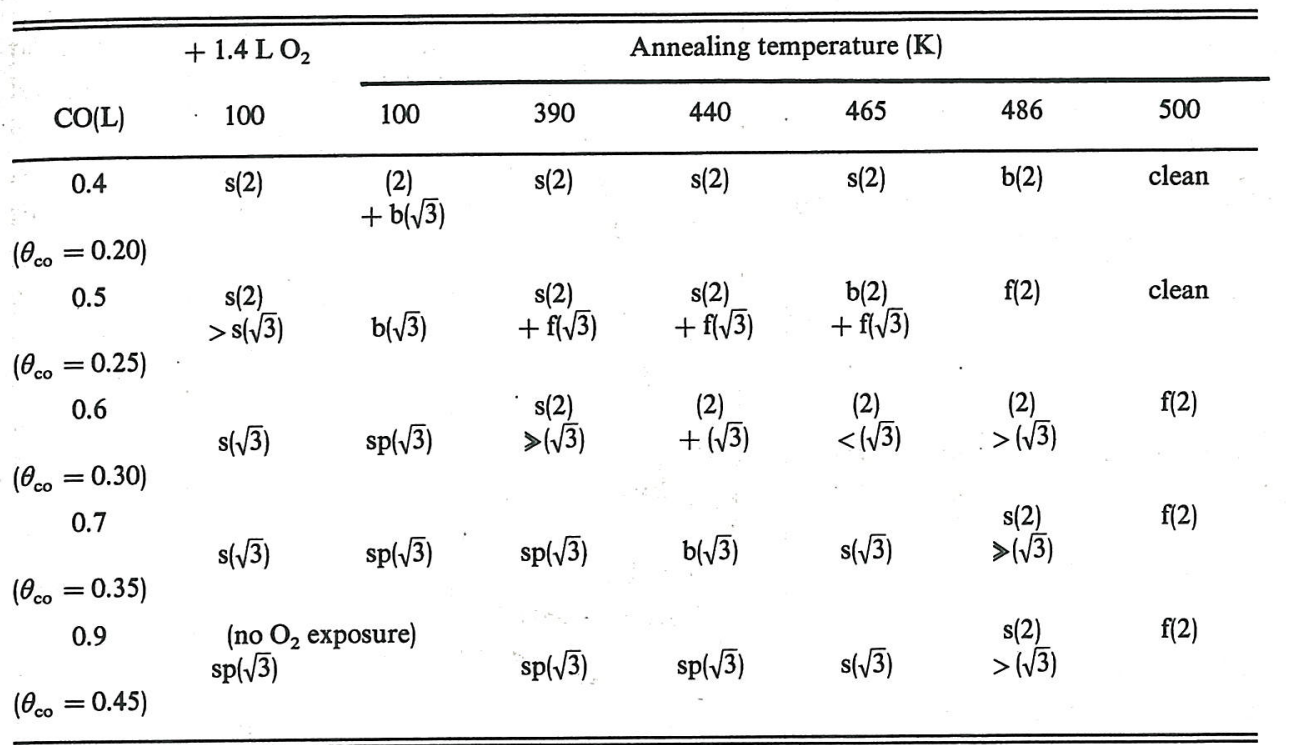

${ }^{a} \theta_{\text {co }}$ CO coverage. LEED pattern; $(2)=(2 \times 2),(\sqrt{3})=(\sqrt{3} \times \sqrt{3}) R 30^{\circ}$. Diffraction spot; + : coexistence, $<$ : more intense, $\ll$ : much more intense, s: sharp, b: broad, f: faint, and sp: split.

tern sequence with a decreasing amount of $\mathrm{CO}(a)$ is listed at the bottom of the table, where the surface was exposed to only $0.9 \mathrm{~L} \mathrm{CO}$ and heated sequentially. The above results can be explained by assuming that the surface is essentially covered by separate domains of $\mathrm{CO}$ and oxygen adatoms, as follows:

(i) $\mathrm{CO}(a)<\mathrm{O}(a)$, i.e., $0.4 \mathrm{~L} \mathrm{CO}$. $(2 \times 2)$-O domains remain throughout heating procedures. The superposition of $(2 \times 2)-\mathrm{O}$ and $(\sqrt{3}) \mathrm{R} 30-\mathrm{CO}$ is not confirmed.

(ii) $\mathrm{CO}(a) \gtrsim \mathrm{O}(a)$, i.e., $0.5-0.6 \mathrm{~L} \mathrm{CO}(\sqrt{3}) \mathrm{R} 30-\mathrm{CO}$ domains are predominant at low temperatures. Heating to 390 $\mathrm{K}$ results in a well-ordered $(2 \times 2)-\mathrm{O}$ : By annealing to 440 $465 \mathrm{~K}, \mathrm{O}(a)$ domains are consumed and $(\sqrt{3}) \mathrm{R} 30-\mathrm{CO}$ becomes sharp. Further heating reduces the $\mathrm{CO}$ coverage, yielding $(2 \times 2)-\mathrm{CO}$ at $\theta_{\text {co }}=1 / 4$. (iii) $\mathrm{CO}(a) \gg \mathrm{O}(a)$, i.e., above $0.7 \mathrm{~L} \mathrm{CO}$. The surface shows LEED patterns almost the same as those without $\mathrm{O}_{2}$ exposures.

Table II lists LEED patterns when CO was exposed after $\mathrm{O}_{2}$ exposure at $100 \mathrm{~K}$ and annealing to $220 \mathrm{~K}$. Above $0.7 \mathrm{~L} \mathrm{O}_{2}$, only the $(2 \times 2)$-O structure was observed even after $\mathrm{CO}$ exposure. The intensity was increased by annealing above $300 \mathrm{~K}$. No $(\sqrt{3}) \mathrm{R} 30-\mathrm{CO}$ was observed. The superposition of the two structures was observed at $0.35 \mathrm{~L} \mathrm{O}_{2}$ or less. The $(2 \times 2)-\mathrm{O}$ became broad after $\mathrm{CO}$ exposure at $100 \mathrm{~K}$. When $\mathrm{CO}$ exposure was $0.9 \mathrm{~L}$, the superposition of sharp $(2 \times 2)$ and $(\sqrt{3}) \mathrm{R} 30-\mathrm{CO}$ was observed, after annealing to 390 $\mathrm{K}$. The intensity of the $(2 \times 2)$ first decreased and that of $(\sqrt{3})$ R30-CO increased. Furthermore, the $(2 \times 2)$ became intense more than $(\sqrt{3}) \mathbf{R} 30-\mathrm{CO}$. For the same reason described

TABLE II. LEED patterns observed when $\mathrm{O}_{2}$ and then $\mathrm{CO}$ were dosed. The surface was first exposed to various amounts of $\mathrm{O}_{2}$ and annealed to $220 \mathrm{~K}$. It was further exposed to $\mathrm{CO}$ at $100 \mathrm{~K}$ and heated sequentially. LEED patterns were observed at $100 \mathrm{~K} .^{\mathrm{a}}$

\begin{tabular}{|c|c|c|c|c|c|c|c|}
\hline \multirow[b]{2}{*}{$\mathrm{O}_{2}(\mathrm{~L})$} & \multirow[b]{2}{*}{$+\mathrm{CO}(\mathrm{L})$} & \multicolumn{6}{|c|}{ Annealing temperature $(\mathrm{K})$} \\
\hline & & 100 & 390 & 440 & 465 & 485 & 500 \\
\hline \multirow{3}{*}{$\begin{array}{c}0.35 \\
\left(\theta_{0}=0.25\right)\end{array}$} & 0.3 & $b(2)$ & $s(2)$ & $s(2)$ & $b(2)$ & $f(2)$ & clean \\
\hline & 0.9 & (2) & $\begin{array}{l}(2) \\
+(\sqrt{3})\end{array}$ & $\begin{array}{c}(2) \\
<(\sqrt{3})\end{array}$ & $\begin{array}{c}(2) \\
>(\sqrt{3})\end{array}$ & $f(2)$ & clean \\
\hline & 1.2 & $\mathrm{~b}(2)$ & $\operatorname{sp}(\sqrt{3})$ & $\mathbf{s}(2)$ & $b(2)$ & $(2)$ & $f(2)$ \\
\hline $\begin{array}{c}0.71 \\
\left(\theta_{0}=0.50\right)\end{array}$ & 1.2 & (2) & (2) & $\begin{array}{c}+(\sqrt{3}) \\
(2)\end{array}$ & $\begin{array}{c}<(\sqrt{3}) \\
(2)\end{array}$ & $\begin{array}{c}>(\sqrt{3}) \\
(2)\end{array}$ & (2) \\
\hline $\begin{array}{c}1.4 \\
\left(\theta_{0}=0.87\right)\end{array}$ & 1.2 & (2) & (2) & (2) & (2) & (2) & (2) \\
\hline
\end{tabular}

${ }^{\mathrm{a}} \theta_{0}$ : oxygen coverage relative to the maximum thermal desorption peak area. The other notations; see Table I. 
above, the $(2 \times 2)$ below $440 \mathrm{~K}$ can be assigned to $(2 \times 2)-\mathrm{O}$ and the $(2 \times 2)$ above $465 \mathrm{~K}$ to $(2 \times 2)-\mathrm{CO}$ at $\theta_{\mathrm{co}}=1 / 4$. The results can be explained as follows: When $\mathrm{CO}(a)<\mathrm{O}(a)$, i.e., $0.35 \mathrm{~L} \mathrm{O}_{2}$ and $0.3 \mathrm{~L} \mathrm{CO}$, or above $0.7 \mathrm{~L} \mathrm{O}_{2},(2 \times 2)$-O domains are predominant throughout the above procedures. At $\mathrm{CO}(a)>\mathrm{O}(a)$, i.e., $0.35 \mathrm{~L} \mathrm{O}_{2}$ and $0.9-1.2 \mathrm{~L} \mathrm{CO},(2 \times 2)-\mathrm{O}$ and $(\sqrt{3})$ R30-CO domains coexist. Further heating removes oxygen adatoms, producing $(\sqrt{3}) \mathrm{R} 30-\mathrm{CO}$ and then $(2 \times 2)-\mathrm{CO}$ at $\theta_{\mathrm{co}}=1 / 4$. It can be concluded that the surface is essentially covered by separate domains of $\mathrm{CO}(a)$ and $\mathrm{O}(a)$.

\section{DISCUSSION}

In this section we will discuss the mechanism of the formation of $\beta_{1}-\mathrm{CO}_{2}$ and $\beta_{2}-\mathrm{CO}_{2}$, and also their angular distributions.

\section{A. Reaction mechanism}

The present experimental results of $\mathrm{CO}_{2}$ formation are essentially the same as those on polycrystalline $\mathrm{Rh} .{ }^{14}$ On polycrystalline $\mathrm{Rh}$, however, $\mathrm{CO}_{2}$ formation started at temperatures much lower than on $\mathrm{Rh}(111)$. Significant $\mathrm{CO}_{2}$ formation from coadsorbed layers of $\mathrm{CO}(\mathrm{a})$ and $\mathrm{O}(\mathrm{a})$ was noticed in the range of $150-500 \mathrm{~K}$ on polycrystalline $\mathrm{Rh}$. The peak positions of $\beta_{1}-\mathrm{CO}_{2}$ and $\beta_{2}-\mathrm{CO}_{2}$ were around $300-400$ and $300 \mathrm{~K}$, respectively. On $\mathrm{Rh}(111), \beta_{1}$ - and $\beta_{2}-\mathrm{CO}_{2}$ peaked in the range of 400-500 and around $400 \mathrm{~K}$. Similar phenomena have been reported on platinum. On $\operatorname{Pt}(111)^{12,27} \mathrm{CO}_{2}$ formation peaked around $300 \mathrm{~K}$ with a narrow peak width. On the other hand $\mathrm{CO}_{2}$ showed broad peaks in the range of $100-400 \mathrm{~K}$ on stepped (321). surfaces. ${ }^{28}$ Such broad $\mathrm{CO}_{2}$ peaks were rationalized by proposing that the activation energy for reaction of terrace and step $\mathrm{CO}$ with terrace and step atomic oxygen was sufficiently different. ${ }^{28}$ Therefore it is likely that the activation energy determined on polycrystalline $\mathrm{Rh}^{29-31}$ is smaller than that on $\mathrm{Rh}(111)$.

Two $\mathrm{CO}_{2}$ formation peaks are reminiscent of similar phenomena on $\operatorname{Pd}(111)$ at low temperatures reported by Conrad et al. ${ }^{32}$ They observed surface processes for $\mathrm{CO}_{2}$ formation quite similar to the $\beta_{1}-\mathrm{CO}_{2}$ and $\beta_{2}-\mathrm{CO}_{2}$ in the present work. They concluded from LEED, UPS, and TDS experiments that under certain conditions the $\mathrm{CO}$ admolecules and oxygen adatoms form separate domains and a true coadsorbate phase, depending on the amount of $\mathrm{CO}$ exposure. The former (separate domains) yielded a $\mathrm{CO}_{2}$ desorption peak at temperatures higher than that from the latter (coadsorbate phase). The reaction mechanism on $\mathrm{Rh}(111)$ is essentially the same as in this model. Over $\mathrm{Rh}(111)$, oxygen adatoms coalesce into domains of the $(2 \times 2)$ structure. This island formation is accelerated by heating the surface above $200 \mathrm{~K} .{ }^{22}$ After this heating the surface is partially covered by oxygen domains of the $(2 \times 2)$ structure. $\mathrm{CO}$ is adsorbed preferentially on the clean parts outside the domains. The surface is covered by separate domains of $\mathrm{CO}$ and oxygen. The interaction between $\mathrm{CO}(a)$ and $\mathrm{O}(a)$ occurs outside the domains or on the perimeters. This interaction yields $\beta_{1}-\mathrm{CO}_{2}$. When the oxygen coverage is small, the oxygen domains are also small and distributed randomly. The kinetics of $\beta_{1}-\mathrm{CO}_{2}$ formation behaves like a second order reaction, i.e., the peak position of

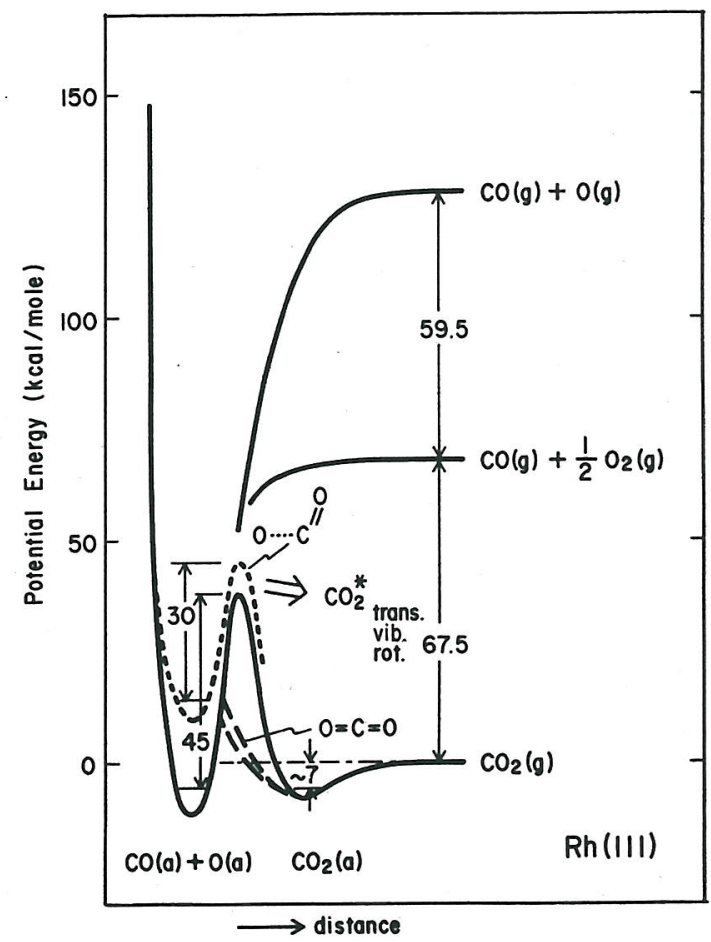

FIG. 16. Potential energy diagram for $\mathrm{CO}_{2}$ formation. All energies are in $\mathrm{kcal} / \mathrm{mol}$.

$\mathrm{CO}_{2}$ shifts to lower temperatures with increasing $\mathrm{CO}$ exposure (Fig. 5). When the oxygen coverage increases, the oxygen domains grow. The interaction between $\mathrm{CO}(a)$ and $\mathrm{O}(a)$ occurs mostly on the perimeters of oxygen domains. The surface diffusion of the reactants is limited by large domains of oxygen. Therefore the kinetics is no longer akin to a second order reaction. When $\mathrm{CO}$ exposure is increased, $\mathrm{CO}$ begins adsorbing in oxygen domains. These $\mathrm{CO}$ admolecules interact strongly with oxygen adatoms, since the distance of $\mathrm{CO}(a)$ to $\mathrm{O}(a)$ is short. This interaction is probably repulsive. ${ }^{32}$ Hence the adsorption energy of $\mathrm{CO}(a)$ and $\mathrm{O}(a)$ will be reduced. The activation energy of $\mathrm{CO}_{2}$ formation is reduced and the resultant $\beta_{2}-\mathrm{CO}_{2}$ is formed at lower temperatures. When the surface is initially saturated with oxygen adatoms, $\mathrm{CO}$ is not adsorbed on clean surfaces. $\mathrm{CO}$ is adsorbed in the oxygen domains, so that only $\beta_{2}-\mathrm{CO}_{2}$ is formed even at small $\mathrm{CO}$ exposures. When $\mathrm{CO}$ is first dosed, only $\beta_{1}-\mathrm{CO}_{2}$ is formed. In this case $\mathrm{CO}$ cannot adsorb in oxygen domains.

A potential energy diagram illustrating the $\mathrm{CO}_{2}$ formation is shown in Fig. 16. The abscissa (distance from the surface) is drawn only in a qualitative sense. The initial state of the $\mathrm{CO}_{2}$ formation consists of $\mathrm{CO}(a)$ and $\mathrm{O}(a)$. The potential energy of this state can be evaluated from the heat of adsorption of $\mathrm{CO}$ and $\mathrm{O}_{2}$. Thiel et al. found that the initial heat of adsorption of $\mathrm{CO}$ on $\mathrm{Rh}(111)$ is $31.6 \mathrm{kcal} / \mathrm{mol} .{ }^{26} \mathrm{The}$ initial heat of dissociative adsorption of oxygen is $85 \mathrm{kcal} /$ $\mathrm{mol}$ on $\mathrm{Rh}(100) \cdot{ }^{20}$ The heat of the adsorption on $\mathrm{Rh}(111)$ by Thiel et al., $56 \mathrm{kcal} / \mathrm{mol},{ }^{22}$ was not used here, since the initial dissolution of oxygen was noted to be significant. The energy of $\mathrm{CO}(a)+\mathrm{O}(a)$ is $74.1 \mathrm{kcal} / \mathrm{mol}$ below the level of $\mathrm{CO}(g)+1 / 2 \mathrm{O}_{2}(g)$. The heat of the reaction $\mathrm{CO}(g)+1 / 2$ $\mathrm{O}_{2}(g) \rightarrow \mathrm{CO}_{2}(g)$ is $67.5 \mathrm{kcal} / \mathrm{mol} .^{33}$ The dissociation energy of 
$\mathrm{O}_{2}$ is $119 \mathrm{kcal} / \mathrm{mol}^{33}$ The energy level of $\mathrm{CO}_{2}(g)$ is adjusted to zero.

The activation energy of $\beta_{1}-\mathrm{CO}_{2}$ formation at small exposures was $45 \mathrm{kcal} / \mathrm{mol}$. It decreased to $35 \mathrm{kcal} / \mathrm{mol}$ at large $\mathrm{CO}$ exposures. This decrease may be attributed to the increased repulsion between coadsorbed reactants. ${ }^{17,18}$ The potential energy of the activated complex is much higher than the heat of adsorption of $\mathrm{CO}_{2}, 6-7 \mathrm{kcal} / \mathrm{mol} .{ }^{14}$ Therefore desorbed $\mathrm{CO}_{2}$ may have higher internal or kinetic energies than when it is in equilibrium with the surface temperature. $\beta_{2}-\mathrm{CO}_{2}$ is formed from the interaction between $\mathrm{O}(a)$ and $\operatorname{CO}(a)$ in the oxygen domain. The energy shift of the initial state was estimated as $20 \mathrm{kcal} / \mathrm{mol}$. The heat of adsorption of $\mathrm{CO}$ in the oxygen domains was estimated to be 23 $\mathrm{kcal} / \mathrm{mol}$ from the low temperature peak of $\mathrm{CO}$ in Fig. 1. The heat of dissociative adsorption of oxygen is $60 \mathrm{kcal} / \mathrm{mol}$ at high oxygen coverages on $\mathrm{Rh}(100){ }^{20}$ The activation energy for the $\beta_{2}-\mathrm{CO}_{2}$ formation is $30 \mathrm{kcal} / \mathrm{mol}$. This upward shift of the potential energy curve (drawn by the dotted line) yields an increase in the potential energy of the activated state by about $7 \mathrm{kcal} / \mathrm{mol}$. This increment can produce a sharper angular distribution of $\mathrm{CO}_{2}$ formation. The level of the zero point energy is drawn only for the adsorption states.

\section{B. Angular distribution}

The $\mathrm{CO}_{2}$ desorption from the physisorption state shows a simple cosine distribution. ${ }^{14}$ The sharp angular distribution of the reaction product indicates that it leaves the surface with an excess translational energy perpendicular to the surface, without being trapped in the physisorption state. The origin of such an excess translational energy of desorbing molecules was typically explained by a simple one-dimensional model proposed by Willigen. ${ }^{1}$ The angular distribution is related to the activation barrier perpendicular to the surface. Recent work by Comsa's group ${ }^{3-6}$ showed that this simple model still can be used as a prototype to explain the general features of the angular and velocity distributions. This model predicts that the mean kinetic energy of desorbing molecules increases with the increase in the desorption angle. Experiments, however, have shown the opposite trend. ${ }^{19}$ Recently, Toya and his co-workers have succeeded in explaining the angular and velocity distribution of desorbing hydrogen molecules. ${ }^{7}$ They used Willigen's model and introduced restricted vibrations of the activated complex parallel to the surface plane. The depth of this potential for restricted vibrations and also the potential energy of the activated complex can be determined from the detailed determination of the velocity distributions. Such experiments are not available at present, hence the Willigen model was used to roughly estimate the energy converted into the translational form. The desorption rate at each angle is a function of the ratio $\epsilon$ of the activation energy converted into the translational form $E$ to the thermal energy at the surface temperature $R T$ as follows:

$$
\begin{aligned}
& I(\theta)=I(\theta=0) \frac{\epsilon+\cos ^{2} \theta}{(\epsilon+1) \cos \theta} e^{-\epsilon \tan ^{2} \theta}, \\
& \epsilon \equiv E / R T,
\end{aligned}
$$

where $I(\theta)$ and $I(\theta=0)$ are the desorption flux at $\theta$ and $\theta=0$, respectively. From the angular distribution, $\epsilon$ was estimated to be 2 for the curve of $\cos ^{4} \theta$. The peak temperature of $\beta_{1}-\mathrm{CO}_{2}$ was $430-500 \mathrm{~K}$. $E$ is roughly $2 \mathrm{kcal} / \mathrm{mol}$. The value for $\beta_{2}-\mathrm{CO}_{2}$ is $6 \mathrm{kcal} / \mathrm{mol}$. These values must be underestimated, since no restricted vibrations are considered. ${ }^{7}$ They, however, may not be far from the true values. This energy essentially originates from the repulsive force between the surface and nascent $\mathrm{CO}_{2}$ molecules. Stable linear $\mathrm{CO}_{2}$ molecules are adsorbed in the physisorption state. The adsorption energy, $6-7 \mathrm{kcal} / \mathrm{mol}$, is quite close to the heat of sublimation of solid carbon dioxide $8.4 \mathrm{kcal} / \mathrm{mol}$. van der Waals' force plays a major role in the adsorption bonding. The equilibrium position is a few angstroms from the surface plane (van der Waals' radii). The position of the $\mathrm{CO}_{2}$ formation is between the surface plane and the equilibrium position of the physisorption. The reactants $\mathrm{CO}(a)$ and $\mathrm{O}(a)$ are chemisorbed and their equilibrium positions are close to the surface. Nascent $\mathrm{CO}_{2}$ molecules receive significant repulsive force the very instant that they are produced. This force increases the velocity of the product $\mathrm{CO}_{2}$ along the surface normal. A potential energy curve yielding the above repulsive force is drawn by the dashed curves (designated by linear $\mathrm{CO}_{2}$ ) in Fig. 16. The energy at the $\mathrm{CO}_{2}$ formation position must be several $\mathrm{kcal} / \mathrm{mol}$ above the $\mathrm{CO}_{2}(g)$ level. When the coverages are increased, this potential energy curve will be shifted upward, because the distance from the position of the $\mathrm{CO}_{2}$ formation to the adsorbates is shorter than to the surface metal. This can explain that the desorption of $\beta_{2}-\mathrm{CO}_{2}$ produced in the oxygen domain is sharper than that of $\beta_{1}-\mathrm{CO}_{2}$. The latter is produced outside the domain or on the perimeter. Therefore it is possible that the $\beta_{1}$ $\mathrm{CO}_{2}$ formation occurs in an invariant chemical environment. The potential energy of the activated complex is about $38 \mathrm{kcal} / \mathrm{mol}$ for $\beta_{1}-\mathrm{CO}_{2}$ and $45 \mathrm{kcal} / \mathrm{mol}$ for $\beta_{2}-\mathrm{CO}_{2}$, relative to the $\mathrm{CO}_{2}(g)$ level. The energy converted into the translational form is only several $\mathrm{kcal} / \mathrm{mol}$. The remnant energy is probably released in the vibrational and rotational form of nascent $\mathrm{CO}_{2}$ molecules and also consumed by the interactions with surfaces. The latter involves rearrangements of surface atoms due to removal of oxygen adatoms and chemisorbed $\mathrm{CO}$ and also excitations of surface phonons. A bent configuration of the activated complex has been proposed by analysis of the kinetic isotope effect on the $\mathrm{CO}_{2}$ formation rate over $\mathrm{NiO}^{34}$ Recent theoretical work predicted a similar configuration on $\mathrm{Pt}(111) .{ }^{35}$ In this case the activation energy is partially used to change the angle of $\mathrm{O}(a)$ ... $\mathrm{C}=\mathrm{O}(a)$, as well as to overcome the repulsion between $\mathrm{O}(a)$ and $\mathrm{CO}(a)$. Such an energy may be released in the internal form of $\mathrm{CO}_{2}$. Recent experiments using infrared emis$\operatorname{sion}^{36,37}$ revealed that the product molecules on polycrystalline Pt surfaces were vibrationally and also rotationally hotter than the surface. Their temperatures with a $\mathrm{Pt}$ foil at $775 \mathrm{~K}$ were estimated to be around $2000 \mathrm{~K} .{ }^{36}$ The excess internal energy is around $10 \mathrm{kcal} / \mathrm{mol}$ or less in this case. A similar situation may be predicted on $\mathrm{Rh}(111)$, since the adsorption behavior of $\mathrm{CO}$ and oxygen is quite similar to that on $\mathrm{Pt}(111)$. Furthermore the CO oxidation shows similar kinetics on both surfaces. Therefore it can be surmised that the 
energy of the activated complex is mostly spent on the interactions with surfaces.

${ }^{1}$ W. van Willigen, Phys. Lett. A 28, 80 (1968).

${ }^{2}$ G. Comsa, Proceedings of the 7th International Vacuum Congress and 3rd International Conference Solid Surfaces, edited by R. Dobrozemsky et al. (Vienna, 1977), p. 1317.

${ }^{3}$ G. Comsa and R. David, Chem. Phys. Lett. 49, 512 (1977).

${ }^{4} \mathrm{G}$. Comsa, R. David, and B. J. Schumacher, Proceedings of the 4 International Conference on Solid Surfaces and 3rd European Conference on Surface Sciences, edited by D. A. Degras and M. Costa (Cannes 1980), p 252. ${ }^{5}$ G. Comsa, R. David, and B. J. Schumacher, Surf. Sci. 95, L210 (1980). ${ }^{6} \mathrm{G}$. Comsa and R. David, Surf. Sci. 117, 77 (1982).

${ }^{7}$ T. Toya, Y. Ohno, S. Ishi, and K. Nagai, Proceedings of the 4th International Conference on Solid Surfaces and 3rd European Conference on Surface Sciences, edited by D. A. Degras and M. Costa (Cannes, 1980), p. 141; personal communication (1983).

${ }^{8}$ W. L. Schaich, Phys. Lett. A 64, 133 (1977).

${ }^{9} \mathrm{G}$. Doyen, Proceedings of the 4th International Conference on Solid Surfaces and 3rd European Conference on Surface Sciences, edited by D. A. Degras and M. Costa (Cannes 1980), p. 145; Vacuum 32, 91 (1982).

${ }^{10}$ D. R. Horton, W. F. Banholzer, and R. I. Masel, Surf. Sci. 116, 22 (1982).

${ }^{11}$ P. R. Norton, Surf. Sci. 44, 624 (1974).

${ }^{12}$ T. Matsushima, Surf. Sci. 127, 403 (1983).

${ }^{13}$ T. Matsushima, M. Hashimoto and I. Toyoshima, J. Catal. 58, 303 (1979).

${ }^{14}$ T. Matsushima, J. Catal. 83, 446 (1983).

${ }^{15}$ T. Matsushima, J. Phys. Chem. 88, 98 (1984).

${ }^{16}$ R. L. Palmer and J. N. Smith, J. Chem. Phys. 60, 1453 (1974).
${ }^{17}$ C. T. Campbell, G. Ertl, H. Kuipers, and J. Segner, J. Chem. Phys. 73, 5862 (1980).

${ }^{18}$ T. Engel and G. Ertl, J. Chem. Phys. 69, 1267 (1978).

${ }^{19}$ C. A. Becker, J. P. Cowin, L. Wharton, and D. J. Auerbach, J. Chem. Phys. 67, 3394 (1977).

${ }^{20} \mathrm{G}$. B. Fisher and S. J. Schmieg, J. Vac. Sci. Technol. A 1, 1064 (1983).

${ }^{21}$ T. Matsushima, J. Catal. 85, 98 (1984).

${ }^{22}$ P. A. Thiel, J. T. Yates, Jr., and W. H. Weinberg, Surf. Sci. 82, 22 (1979).

${ }^{23}$ J. Falconer and R. J. Madix, J. Catal. 48, 262 (1977).

${ }^{24}$ P. A. Redhead, Vacuum 12, 203 (1962).

${ }^{25}$ R. J. Koestner, M. A. Van Hove, and G. A. Somorjai, Surf. Sci. 107, 439 (1981).

${ }^{26}$ P. A. Thiel, E. D. Williams, J. T. Yates, Jr., and W. H. Weinberg, Surf. Sci. 84, 54 (1979).

${ }^{27}$ J. L. Gland and E. B. Kollin, J. Chem. Phys. 78, 963 (1983).

${ }^{28}$ J. L. Gland, M. R. McClellan, and F. R. McFeely, J. Vac. Sci. Technol. A 1, 1070 (1983).

${ }^{29}$ C. T. Campbell, S-K. Shi, and J. M. White, J. Vac. Sci. Technol. 16, 605 (1979).

${ }^{30}$ C. T. Campbell, S-K. Shi, and J. M. White, J. Phys. Chem. 83, 2255 (1979).

${ }^{31}$ C. T. Campbell, S-K. Shi, and J. M. White, Appl. Surf. Sci. 2, 382 (1979).

${ }^{32}$ H. Conrad, G. Ertl, and J. Kuippers, Surf. Sci. 76, 323 (1978).

${ }^{33}$ Lange's Handbook of Chemistry 20th, edited by J. A. Dean (McGrawHill, New York, 1979).

${ }^{34}$ T. Kobal, M. Senegacnik, and B. Barlic, J. Chem. Phys., 62, 2740 (1975).

${ }^{35}$ N. K. Ray and A. B. Anderson, Surf. Sci. 119, 35 (1982).

${ }^{36}$ D. A. Mantell, S. B. Ryali, B. L. Halpern, G. L. Haller, and J. B. Fenn, Chem. Phys. Lett. 81, 185 (1981).

${ }^{37}$ S. L. Bernasek and S. R. Leone, Chem. Phys. Lett. 84, 401 (1981). 